\title{
FORMULATION AND EVALUATION OF ESOMEPRAZOLE FAST DISSOLVING BUCCAL FILMS
}

\author{
BALAKRISHNA T ${ }^{1}$, VIDYADHARA S $^{1}$, MURTHY TEGK ${ }^{2}$, RAMU A ${ }^{1}$.SASIDHAR RLC ${ }^{1}$
}

${ }^{1}$ Department of Pharmaceutics, Chebrolu Hanumaiah Institute of Pharmaceutical Sciences, Chandramoulipuram, Chowdavaram, Guntur 522 019, Andhra Pradesh, India. ${ }^{2}$ Department of Pharmaceutics, Bapatla College of Pharmacy, Bapatla, Guntur - 522101, Andhra Pradesh, India. Email: balakrishnathalamanchi@gmail.com

Received: 15 May 2018, Revised and Accepted: 14 June 2018

ABSTRACT

Objective: The present study deals with the formulation and evaluation of fast dissolving buccal films for effective treatment option in the gastroesophageal reflux disease.

Methods: Esomeprazole fast dissolving buccal films are a convenient formulation of which can be taken with or without water. In the present investigation, polyvinyl alcohol and polyvinylpyrrolidone were used as film-forming agents and polyethylene glycol 400 is taken as plasticizer. Solvent evaporation method was used for the preparation of fast dissolving buccal films.

Results: The films were prepared and evaluated for film thickness, folding endurance, dispersion test, drug content, and dissolution. The in vitro dissolution studies were carried out using simulated salivary fluid (pH 6.8 phosphate buffer).

Conclusion: Among all the formulations, Formulation E7 was released up to $99.6 \%$ of the drug from the film within 5 min of time which exhibits faster absorption and also shows desirable characteristics of the film. The drug-excipient interaction studies WERE carried out by Fourier-transform infrared studies, differential scanning calorimetry analysis-X-diffraction studies, and scanning electron microscopic studies and the results revealed that there were no major interactions between the drugs and excipients used for the preparation of films.

Keywords: Fast dissolving buccal films, Esomeprazole, Polyvinyl alcohol, Polyvinylpyrrolidone, Polyethylene glycol 400 solvent evaporation method. (C) 2018 The Authors. Published by Innovare Academic Sciences Pvt Ltd. This is an open access article under the CC BY license (http://creativecommons. org/licenses/by/4. 0/) DOI: http://dx.doi.org/10.22159/ajpcr.2018.v11i10.27321

\section{INTRODUCTION}

Esomeprazole, the new S-isomer of omeprazole, is introduced to reduce gastric acid secretion more efficiently. Esomeprazole exhibits significantly higher bioavailability, leading to the greater inhibition of gastric acid secretion compared to omeprazole [1]. Esomeprazole, the stereospecific S-isomer of Omeprazole, is the first proton-pump inhibitor to be developed as a single isomer for use in the treatment of acid-related diseases [2]. The intragastric $\mathrm{pH}$-monitoring data for esomeprazole, $20 \mathrm{mg}$ once daily, show improvement over omeprazole, $20 \mathrm{mg}$ once daily, but the esomeprazole, $40 \mathrm{mg}$ once daily, intragastric $\mathrm{pH}$ data show a further convincing gain in control of gastric $\mathrm{pH}$ [3]. Early studies have shown that esomeprazole achieves greater and more sustained acid control than omeprazole, with a similar tolerability and safety profile. Furthermore, esomeprazole shows a more rapid onset of acid-suppression effect than omeprazole and less interindividual variation in acid control. In addition, a recent crossover study demonstrated that esomeprazole at a standard dose of $40 \mathrm{mg}$ once daily provides more effective control of gastric acid at steady state than standard doses of pantoprazole, lansoprazole, and rabeprazole in patients with symptomatic gastroesophageal reflux disease (GERD) [4]. In addition, esomeprazole treatment yields higher erosive esophagitis healing rates and provides sustained resolution of heartburn in more patients than any other [5]. GERD is a condition in which the digestive acid in the stomach comes in contact with the esophagus (food pipe). The irritation caused by this disorder is known as heartburn. Longterm contact between the acid and esophagus can cause permanent damage to the esophagus [6,7]. Esomeprazole reduces the production of digestives acids, thus minimizing their effect on the esophagus. Esomeprazole is combined with the antibiotics clarithromycin and amoxicillin (or metronidazole in penicillin-hypersensitive patients) in the 7-14-day eradication triple therapy for Helicobacter pylori. Infection by H. pylori is the causative factor in the majority of peptic and duodenal ulcers [5].

\section{METHODS}

Esomeprazole was procured as gift sample from M/S Aurobindo Pharmaceuticals, Hyderabad. Polyvinyl alcohol (PVA) and polyvinylpyrrolidone (PVP) were commercially procured from M/S Yarrow Chem Products, Mumbai. Polyethylene glycol (PEG) was procured commercially from Sisco Research Laboratories Pvt. Ltd., Mumbai. Saccharin sodium was procured commercially from High-Pure Fine Chemicals, Chennai. All the materials used in the formulation were of pharmacopoeial standards.

Preparation of esomeprazole fast dissolving buccal films (EFDBF) Fast dissolving buccal films of esomeprazole were prepared by solvent evaporation method. Film-forming agents such as PVA and PVP were prepared in the form of aqueous solutions individually in $100 \mathrm{ml}$ beakers to attain clear solutions Then, the solution of PVP was added to PVA aqueous solution and stirred well to get homogenous solution which is marked as solution A. Accurate quantities of esomeprazole and saccharin sodium were weighed individually and dissolved in suitable quantity of PEG 400 to get a drug and plasticizer solution which is marked as solution B. The solution B was added to aqueous solution A and mixed continuously. The obtained solution was drawn on the non-adhesive base plate and dried under infrared (IR) lamp for $24 \mathrm{~h}$. After drying, the films were cut into suitable sizes [8]. Various trials were conducted to carried out optimize formula for the preparation of EFDBF. The various compositions of EFDBF are given in Table 1.

\section{Evaluation of fast dissolving films}

\section{Film thickness}

The film thickness was measured using screw gauge with a least count of $0.01 \mathrm{~mm}$ at different locations on the film. The film thickness was measured at three different locations, and the average weight was determined. The obtained results are given in Table 2 . 
Folding endurance

It was determined by folding the film several times (95 times). The film was found to be having good flexibility without cracking. The film was folded at an angle of $180^{\circ}$ at the same place till it broke or folded up to 100 times without breaking. The studies were performed in Trice and the average mean was calculated.

\section{Uniformity of drug content}

The content of drug uniformity of the films was tested by ultraviolet (UV)-visible spectrophotometric method. The absorbance values were determined at a wavelength of $300 \mathrm{~nm}$. The \% drug content of various films was determined and is given in Table 3 .

\section{Dispersion test}

A film equivalent to $20 \mathrm{mg}$ of esomeprazole was placed in $200 \mathrm{ml}$ of $6.8 \mathrm{pH}$ phosphate buffer and was stirred for $3 \mathrm{~min}$. Then, the resulting solution was passed through sieve number 22 . The film passed the dispersion test only when no residue is left on the screen.

\section{In vitro dissolution study using Franz diffusion cell}

It was determined using Franz diffusion cell with an constant volume of buffer (15 mL) (Fig.2).. The film equivalent to $20 \mathrm{mg}$ of esomeprazole was placed in between the two compartments of an apparatus and pipette $15 \mathrm{ml}$ of $6.8 \mathrm{pH}$ buffer ( $\mathrm{pH}$ of saliva) was added to receptor compartment. Cell is kept on magnetic stirrer and bead in the cell is maintained at a speed of 50 revolution per minute (RPM), and medium was maintained at a temperature of nearly $32^{\circ} \mathrm{C} \pm 0.5^{\circ} \mathrm{C}$ and withdraw $1 \mathrm{ml}$ of samples at various time intervals. The samples were diluted with $6.8 \mathrm{pH}$ phosphate buffer and measured the absorbance at $296 \mathrm{~nm}$ against $6.8 \mathrm{pH}$ Buffer as Blank $[9,10]$. The various dissolution profiles for films are given in shown in Fig. 1. The in vitro dissolution parameters are given in Table 3.

\section{Evaluation of various dissolution parameters}

Based on dissolution data obtained, various dissolution parameters were calculated such as $\mathrm{T}_{50}, \mathrm{~T}_{90}, \mathrm{DE}_{5 \%}$ first-order rate constant, and Hixson-Crowell as shown in Table 3.

\section{Characterization}

Dissolution studies were performed on all the formulations, and among these, formulation E7 was further evaluated by Fourier-transform infrared (FTIR) spectroscopy and differential scanning calorimetry.

\section{FTIR}

The FTIR spectra of esomeprazole, PVP, and PVA were obtained using Bruker FTIR spectrophotometer to study the interaction between drug and carrier in films. The samples were prepared in $\mathrm{KBr}$ discs $(2 \mathrm{mg}$ sample in $200 \mathrm{mg} \mathrm{KBr}$ ), and the sampling range was $400-4000 \mathrm{~cm}^{-1}$ and the resolution was $4 \mathrm{~cm}^{-1}$. The FTIR spectra are shown in Figs. 2 and 3.

\section{Differential scanning calorimetry (DSC)}

DSC measurements were performed on esomeprazole and filmforming agents such as PVP, PVA, and optimized formulation E7 using

Table 1: Composition of EFDBF

\begin{tabular}{|c|c|c|c|c|c|c|c|c|c|c|}
\hline S.No & Ingredients/10 films & E1 & E2 & E3 & E4 & E5 & E6 & E7 & E8 & E9 \\
\hline 1 & Esomeprazole & 200 & 200 & 200 & 200 & 200 & 200 & 200 & 200 & 200 \\
\hline 2 & PVP & 300 & 300 & 300 & 300 & 300 & 300 & 300 & 300 & 300 \\
\hline 3 & PVA & 350 & 400 & 450 & 500 & 550 & 550 & 550 & 550 & 550 \\
\hline 4 & PEG400 & 100 & 100 & 100 & 100 & 100 & 120 & 140 & 160 & 180 \\
\hline 5 & Sodium saccharine & 20 & 20 & 20 & 20 & 20 & 20 & 20 & 20 & 20 \\
\hline 6 & Methanol (ml) & 10 & 10 & 10 & 10 & 10 & 10 & 10 & 10 & 10 \\
\hline
\end{tabular}

EFDBF: Esomeprazole fast dissolving buccal films, PVP: Polyvinylpyrrolidone, PVA: Polyvinyl alcohol, PEG 400: Polyethylene glycol 400

Table 2: Evaluation of in vitro dissolution parameters for EFDBF

\begin{tabular}{|c|c|c|c|c|c|c|c|}
\hline S.No & Formulation & $\begin{array}{l}\text { Weight } \\
\text { uniformity (mg) }\end{array}$ & $\begin{array}{l}\text { Drug content } \\
\text { (mg/film) }\end{array}$ & $\begin{array}{l}\text { Film } \\
\text { thickness (mm) }\end{array}$ & $\begin{array}{l}\text { Dispersion } \\
\text { test }\end{array}$ & $\begin{array}{l}\text { Folding } \\
\text { endurance (\%) }\end{array}$ & Curling \\
\hline 1. & E1 & 84 & 18.777 & 0.034 & Passed & 85 & Absent \\
\hline 2. & E2 & 78 & 18.815 & 0.034 & Passed & 96 & Absent \\
\hline 3. & E3 & 91 & 18.557 & 0.034 & Passed & 92 & Absent \\
\hline 4. & E4 & 96 & 19.440 & 0.034 & Passed & 99 & Absent \\
\hline 5. & E5 & 88 & 18.745 & 0.033 & Passed & 98 & Absent \\
\hline 6. & E6 & 79 & 17.236 & 0.034 & Passed & 95 & Absent \\
\hline 8. & E8 & 99 & 19.65 & 0.032 & Passed & 99 & Absent \\
\hline 9. & E9 & 70 & 17.5698 & 0.032 & Passed & 66 & Absent \\
\hline
\end{tabular}

EFDBF: Esomeprazole fast dissolving buccal films

Table 3: Evaluation of physical parameters for EFDBF

\begin{tabular}{|c|c|c|c|c|c|c|}
\hline \multirow[t]{2}{*}{ S.No } & \multirow[t]{2}{*}{ Formulation } & \multirow[t]{2}{*}{$T_{50}(\min )$} & \multirow[t]{2}{*}{$\mathrm{T}_{90}(\mathrm{~min})$} & \multirow[t]{2}{*}{$\mathrm{DE}_{5 \%}$} & \multicolumn{2}{|c|}{ First order } \\
\hline & & & & & $\mathrm{K}\left(\mathrm{min}^{-1}\right)$ & $\mathbf{R}^{2}$ \\
\hline 1. & E1 & 4.6 & $>15$ & 18.4 & 0.163 & 0.953 \\
\hline 2. & $\mathrm{E} 2$ & 2.5 & $>15$ & 20.5 & 0.181 & 0.966 \\
\hline 3. & E3 & 2.4 & 14.5 & 19.8 & 0.156 & 0.946 \\
\hline 4. & E4 & 2.3 & 10 & 19.6 & 0.234 & 0.954 \\
\hline 5. & E5 & 2.2 & 9.5 & 22.4 & 0.216 & 0.951 \\
\hline 7. & E7 & 0.6 & 4.5 & 27.8 & 0.187 & 0.964 \\
\hline 8. & E8 & 2.3 & 14 & 22.8 & 0.267 & 0.994 \\
\hline 9. & E9 & 2.0 & 14.5 & 24.9 & 0.316 & 0.916 \\
\hline
\end{tabular}

EFDBF: Esomeprazole fast dissolving buccal films 

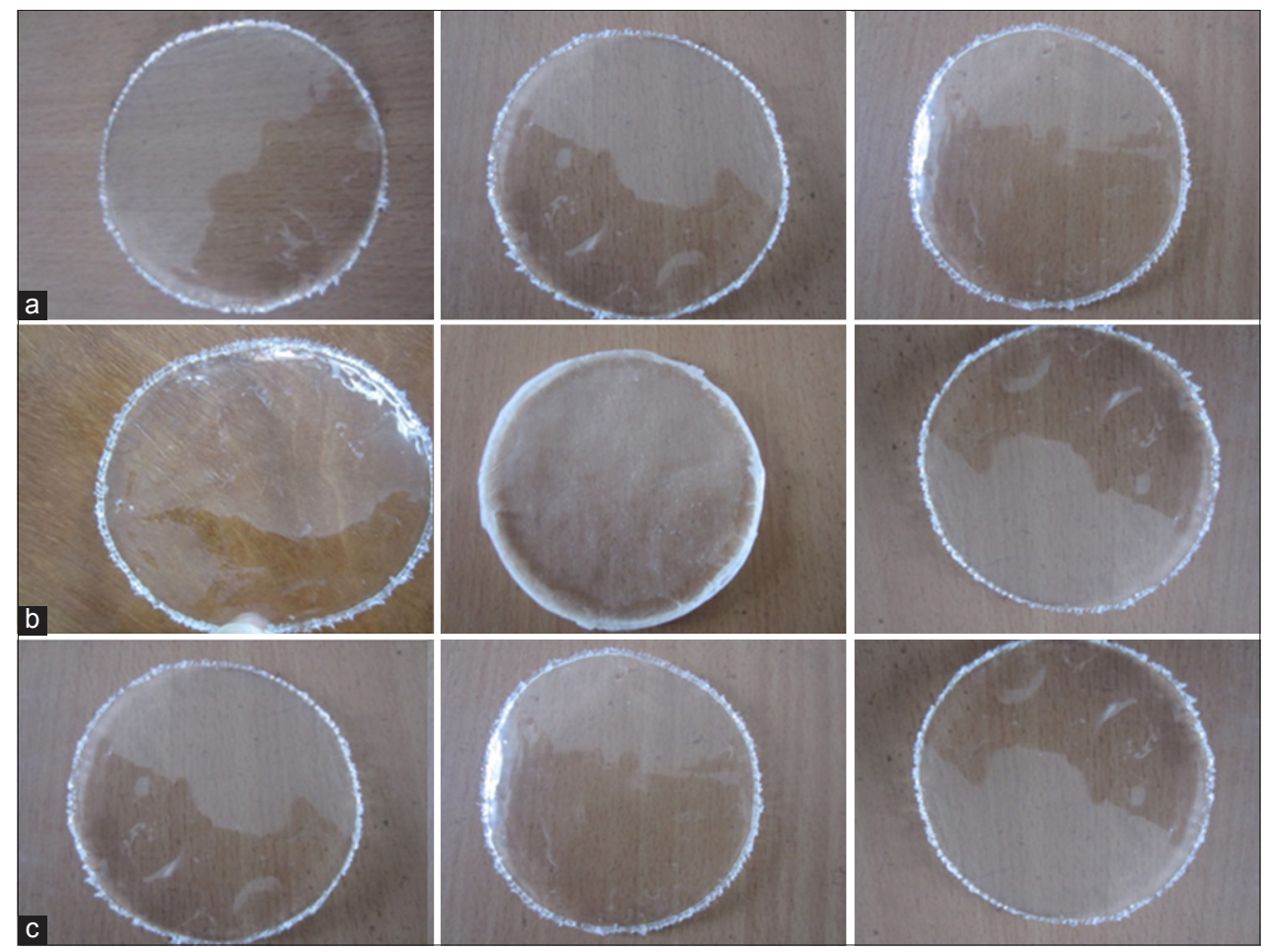

Fig. 1: (a-c) Esomeprazole fast dissolving buccal films

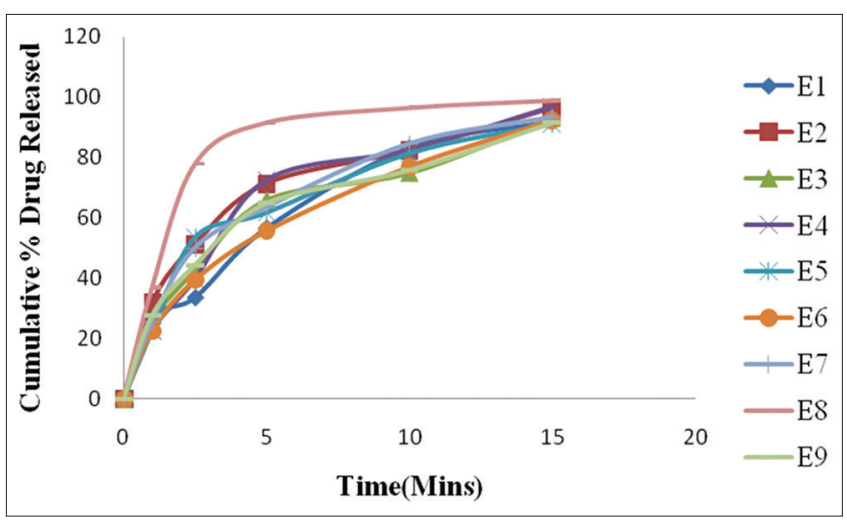

Fig. 2: Drug release profiles for esomeprazole fast dissolving buccal film

differential scanning calorimeter (SHIMZDO and DSC-60). The samples were placed in a sealed aluminum crucible and evaluated with a heating rate of $20^{\circ} \mathrm{C} / \mathrm{min}$ at a temperature range of $25-250^{\circ} \mathrm{C}$. The thermograms were recorded and are shown in Figs. 4-9.

\section{Scanning electron microscope (SEM) analysis}

The SEM photographs were taken for the optimized film formulation E7 and esomeprazole pure drug. The SEM photographs are shown in Figs. 10 and 11. The E7 formulation showed smooth even surface.

\section{X-ray powder diffraction (XRD)}

The powder crystalline of the esomeprazole and the optimized formulation E7 were determined using SHIMADZO XRD-7000 with copper target instrument. The conditions were maintained at $40 \mathrm{Kv}$, with $40 \mathrm{MA}$ at room temperature. The scanning rate employed was $0.1 / \mathrm{s}$ over a range of 2 values from $3^{\circ}$ to $45^{\circ}$. The diffractograms are shown in Figs. 12-15.

\section{RESULTS AND DISCUSSION}

The present investigation deals with the formulation and evaluation of fast dissolving buccal films of esomeprazole which is used for the treatment of acid-related disorders. The main focus on this study was to select the best combination of polymer and excipients to formulate acid-related disorders fast dissolving buccal films. Fast dissolving buccal films were prepared by solvent evaporation method using PVP and PVA. PEG 400 was used as plasticizer to make them pliable and flexible in nature. Saccharin sodium was used as artificial sweetener in the formulation. The films were prepared and evaluated for thickness, folding endurance; drug content uniformity and dispersion time. The composition of various fast dissolving buccal films of acid-related disorders is given in Table 1.

The prepared films were further evaluated for thickness, folding endurance, dispersion test, drug content, and in vitro diffusion studies. The thickness of a film was found in the range of $0.032 \pm 0.001$ $0.034 \pm 0.004 \mathrm{~mm}$. The optimized formulation E7 film is having thickness of $0.034 \mathrm{~mm}$. The folding endurance values of all prepared films ranged from 30 to $100 \%$. The optimized formulation E7 film was found to have the folding endurance of $100 \%$ which is highly beneficial or agreeable. The drug uniformity was found in the range of $19.99 \pm 1.6 \mathrm{mg}$. The optimized formulation E7 film was found to have $19.99 \mathrm{mg}$. The films were further subjected to dispersion test as per the Indian pharmacopeial standard. All the prepared film formulations were found to disperse in $6.8 \mathrm{pH}$ phosphate buffer within $3 \mathrm{~min}$. No inert fibrous or insoluble material was left on the 22 mesh screen when the dispersion was passed through it. The prepared films were subjected to thickness of a film, drug content, folding endurance, and dispersion test values obtained for various fast dissolving buccal films which are given in Table 3.

Fast dissolving buccal films of esomeprazole were further subjected to in vitro dissolution studies using Frantz diffusion cell with $15 \mathrm{ml}$ of 6.8 $\mathrm{pH}$ phosphate buffer as a medium which is maintained at a temperature $32^{\circ} \mathrm{C}$. The dissolution medium in the cell was maintained to rotate at $50 \mathrm{rpm}$ using magnetic stirrer. The samples were withdrawn at various time intervals and were consequently diluted with $6.8 \mathrm{pH}$ phosphate buffer, and absorbance values were noted at $296 \mathrm{~nm}$ using ELICO Double beam spectrophotometer. The obtained dissolution profiles are given in Table 3 and are shown in Fig. 1. Among all the formulations, formulation E7 was found to be best suitable for fast dissolving and 


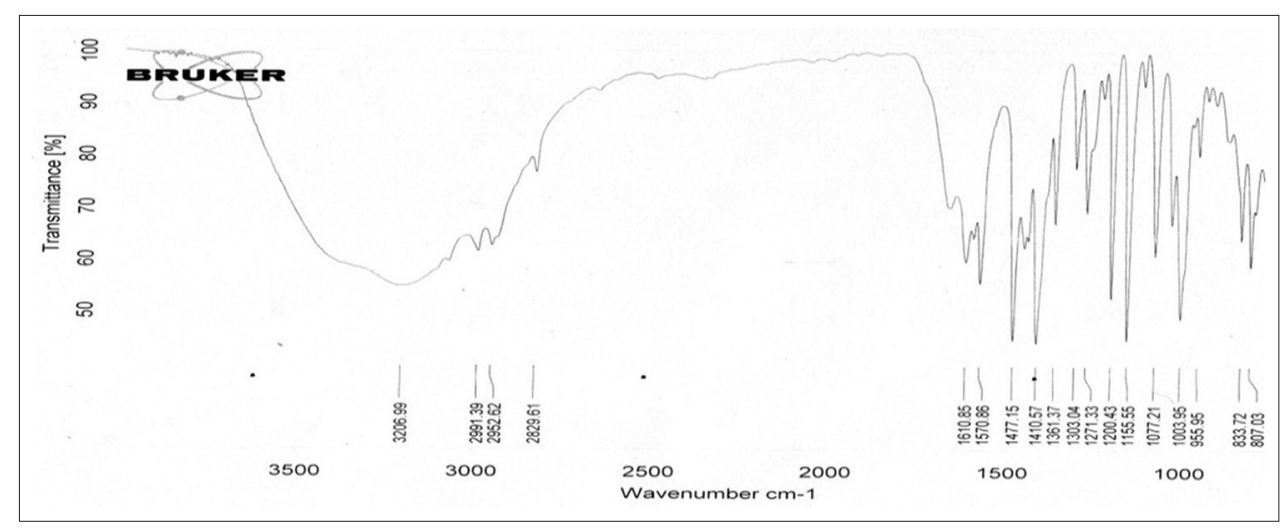

Fig. 3: Fourier-transform infrared spectrum of esomeprazole pure drug

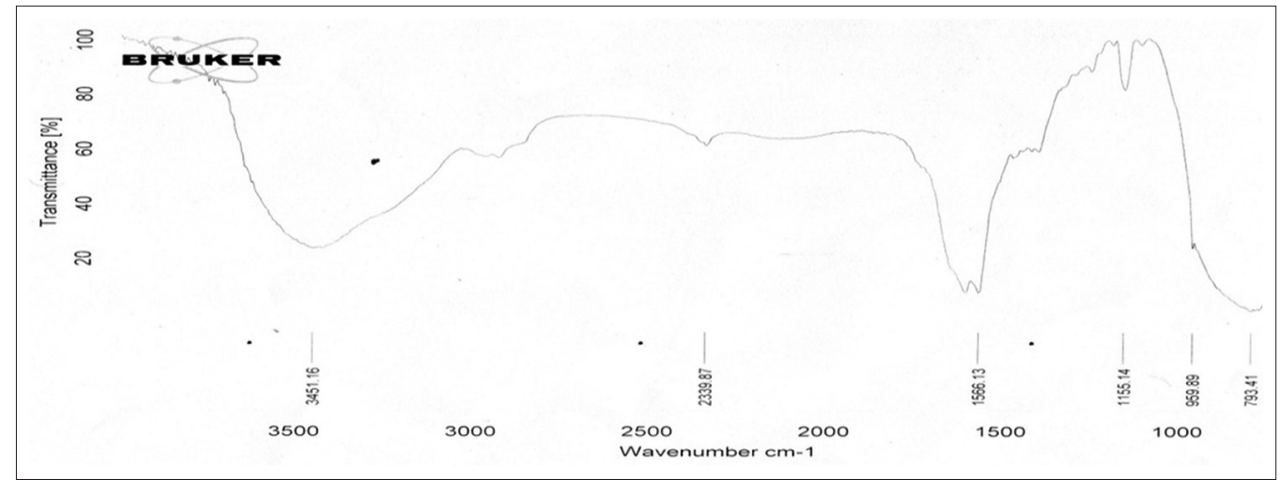

Fig. 4: Fourier-transform infrared spectrum of polyvinylpyrrolidone

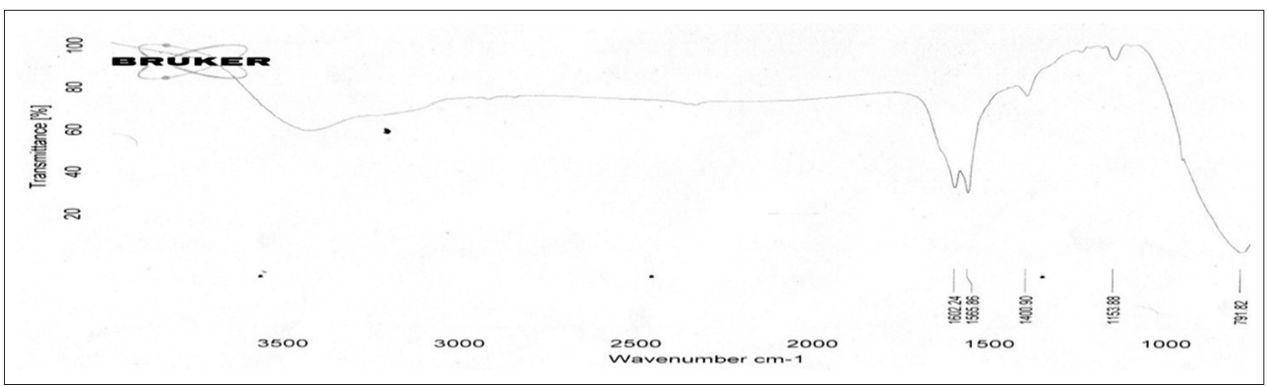

Fig. 5: Fourier-transform infrared spectrum of polyvinyl alcohol

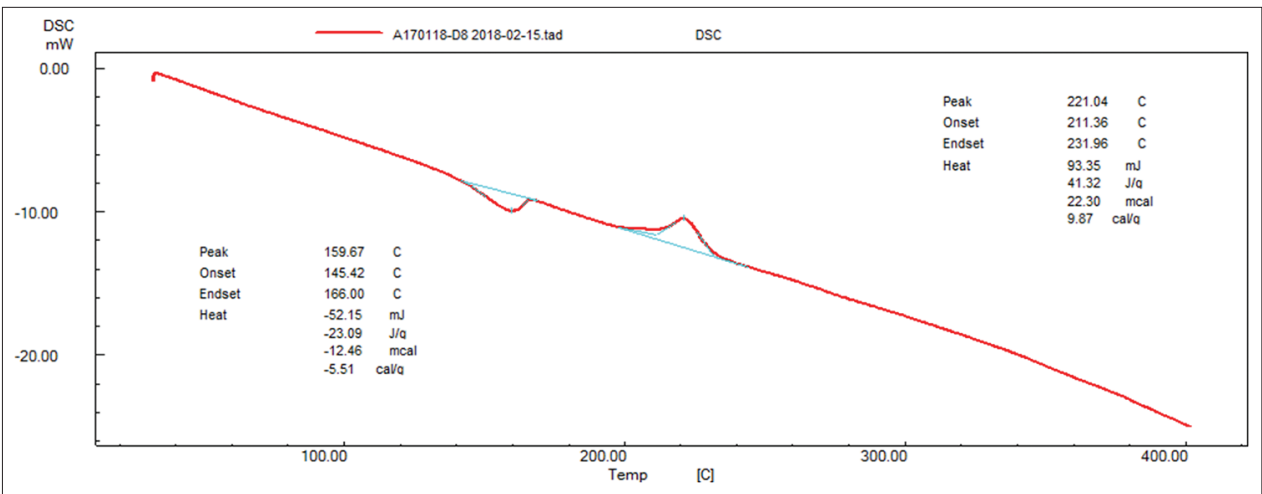

Fig. 6: Differential scanning calorimetry thermogram of esomeprazole pure drug

also this film should possess all the physical characteristics required for the fast dissolving buccal film. The film formulations E7 containing $30 \%$ of PVP and $55 \%$ of PVA were found to exhibit the best filmforming properties with $100 \%$ folding endurance value. These
E8 formulations with $10-16 \%$ of PEG were found to exhibit rapid dispersion in the dissolution media and dissolved readily in the same medium which indicated fast dissolving characteristics of the film. The first-order graphs for various fast dissolving buccal films were found 


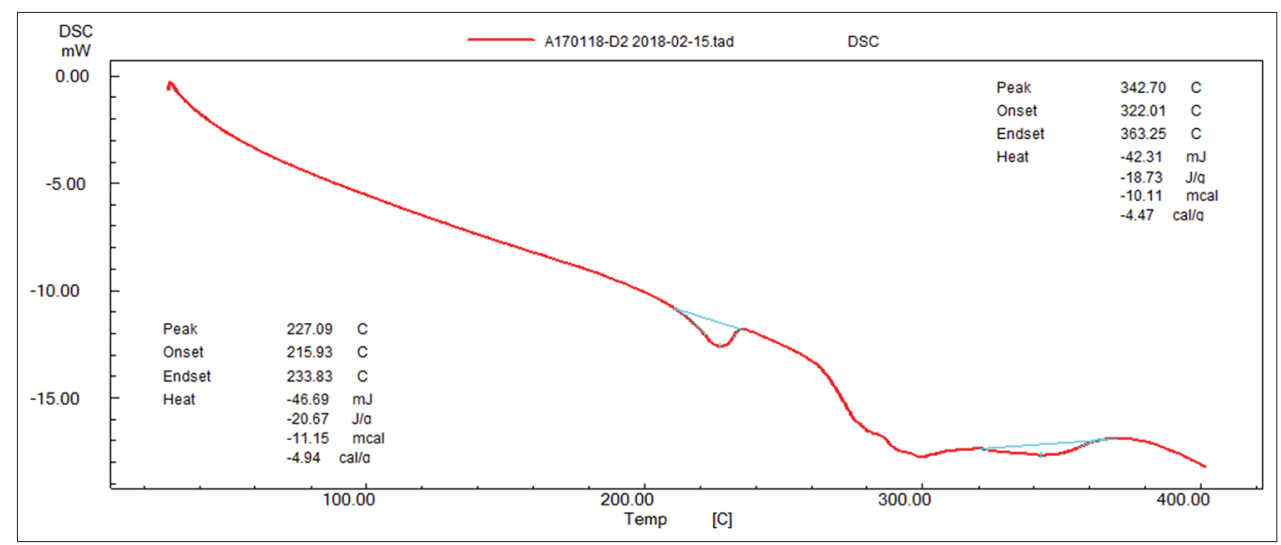

Fig. 7: Differential scanning calorimetry thermogram of polyvinylpyrrolidone

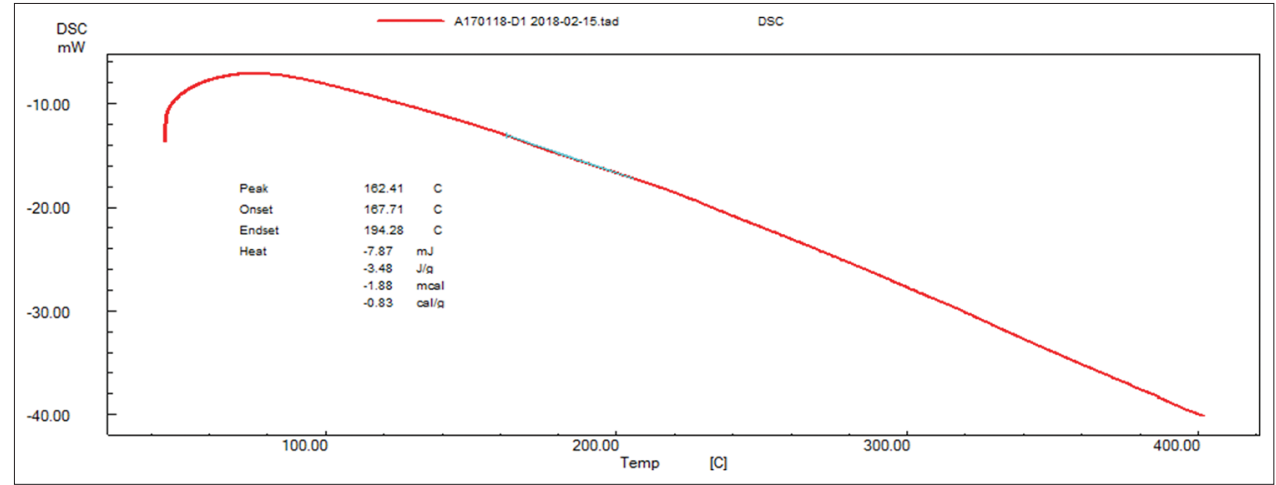

Fig. 8: Differential scanning calorimetry thermogram of polyvinyl alcohol

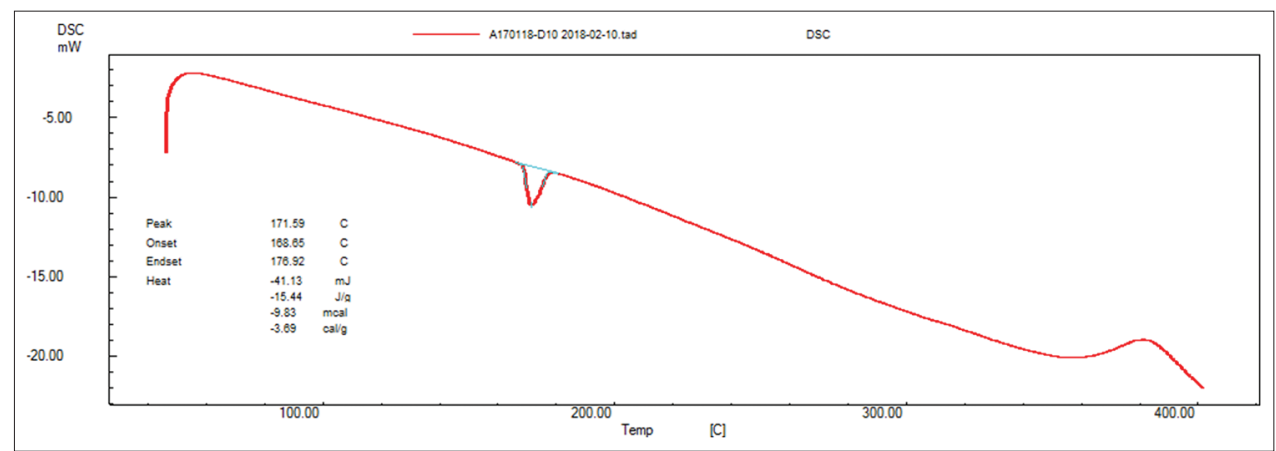

Fig. 9: Differential scanning calorimetry thermogram of optimized formulation E7

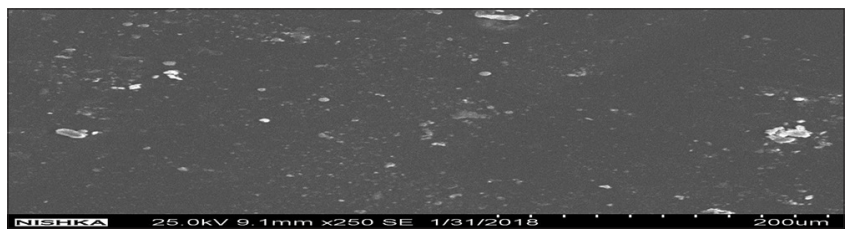

Fig. 10: Scanning electron microscope photograph of esomeprazole pure drug

to be linear with correlation coefficient values obtained which were in the range of 0.926-0.996. It indicated that the drug release from the films was found to be concentration dependent. This indicated that the dissolution of the drug from the film was greatly dependent on weight uniformity of the film that undergoes dissolution per unit time. The formulated films were characterized using FTIR.. The FTIR spectra of the commercial sample of esomeprazole displayed bands at

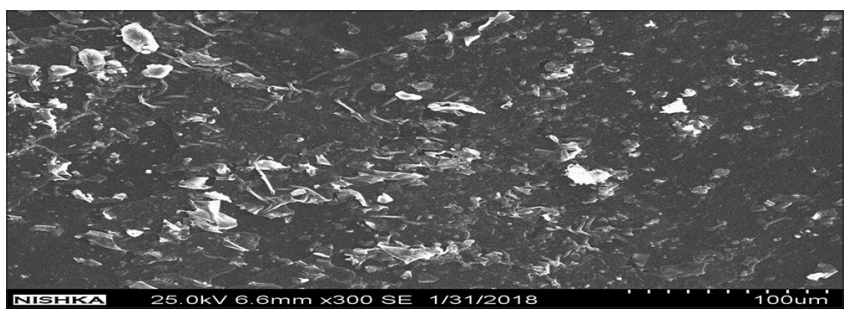

Fig. 11: Scanning electron microscope photograph of optimized film formulation (E7)

$3206 \mathrm{~cm}^{-1}$ due to N-H Stretch and $2952 \mathrm{~cm}^{-1}$ due to C=C Stretching. The IR spectra of drug and film-forming agents indicated that there are no interactions between drug and excipients used. DSC thermographic studies were carried out on esomeprazole pure drug and film-forming agents. The exothermic peak for pure esomeprazole drug was obtained 


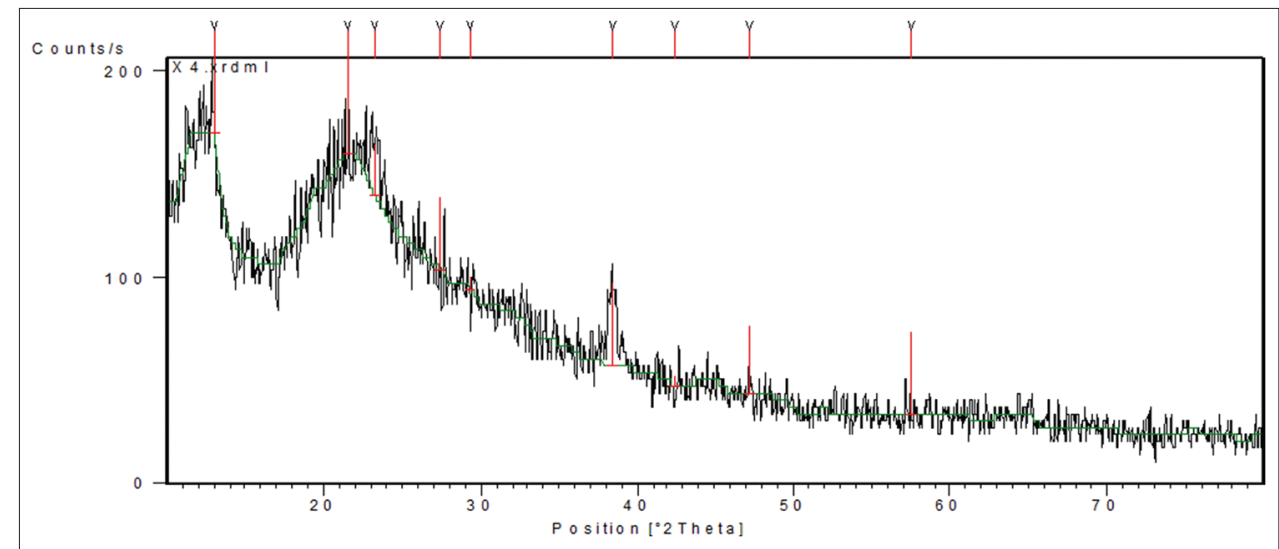

Fig. 12: X-ray powder diffraction spectrum of esomeprazole pure drug

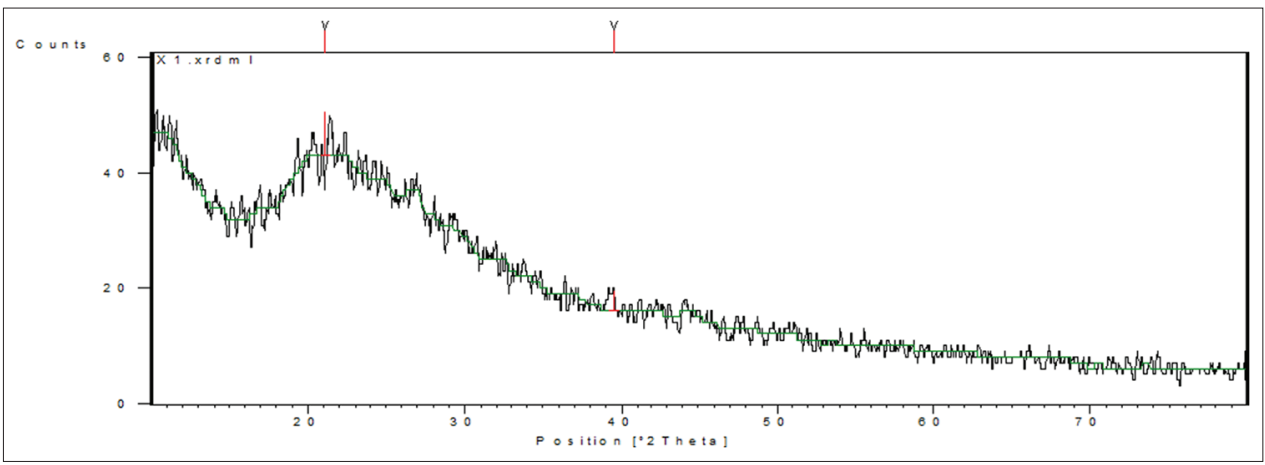

Fig. 13: X-ray powder diffraction spectrum of polyvinylpyrrolidone

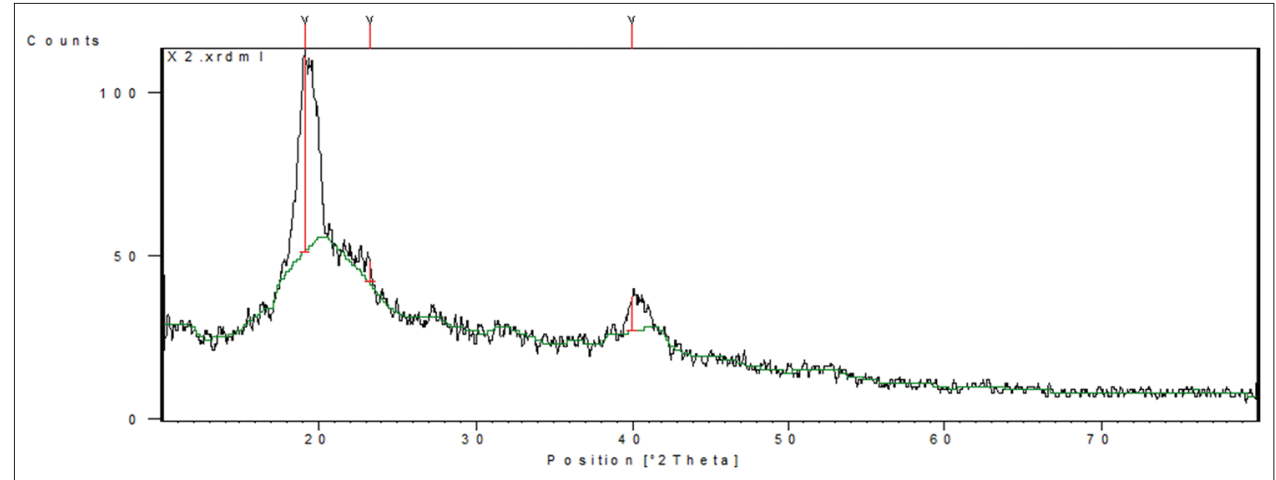

Fig. 14: X-ray powder diffraction spectrum of polyvinyl alcohol

at $159.67^{\circ} \mathrm{C}$. The short broad exothermic peak for PVP was obtained at $227.07^{\circ} \mathrm{C}$. The short exothermic peak for PVA was obtained at $161.41^{\circ} \mathrm{C}$. Optimized formulation E8 was obtained at $171.59^{\circ} \mathrm{C}$. Hence, no interaction between drug and excipients was observed with DSC studies.

The XRD patterns of esomeprazole and film-forming agents such as PVP and PVA and optimized formulation (E7) diffraction patterns of pure esomeprazole showed characteristic high diffraction peaks. On the other hand, the diffraction patterns of optimized formulation (E7) showed a decrease in the peak intensity.

\section{CONCLUSION}

Fast dissolving buccal films of esomeprazole prepared in the present study should exhibit good film properties as indicated by film thickness, and folding endurance was measured. All the films prepared were found to be stable uniform, flexible, pliable, and 99\% of drug was released from optimized film E7 within 5 min of time. This was advisable for fast absorption. Hence, fast dissolving buccal films of esomeprazole were found to be suitable for effective and well-tolerated treatment option in the management of acid-related disorders

\section{ACKNOWLEDGMENTS}

The authors express their gratitude to Aurobindo Pharmaceuticals and Nishika Laboratories, Hyderabad, for providing the gift samples and characterization studies for the samples. The authors are thankful to the management of Chebrolu Hanumaiah Institute of Pharmaceutical Sciences, Guntur, for providing the facilities to carry out the research work. 


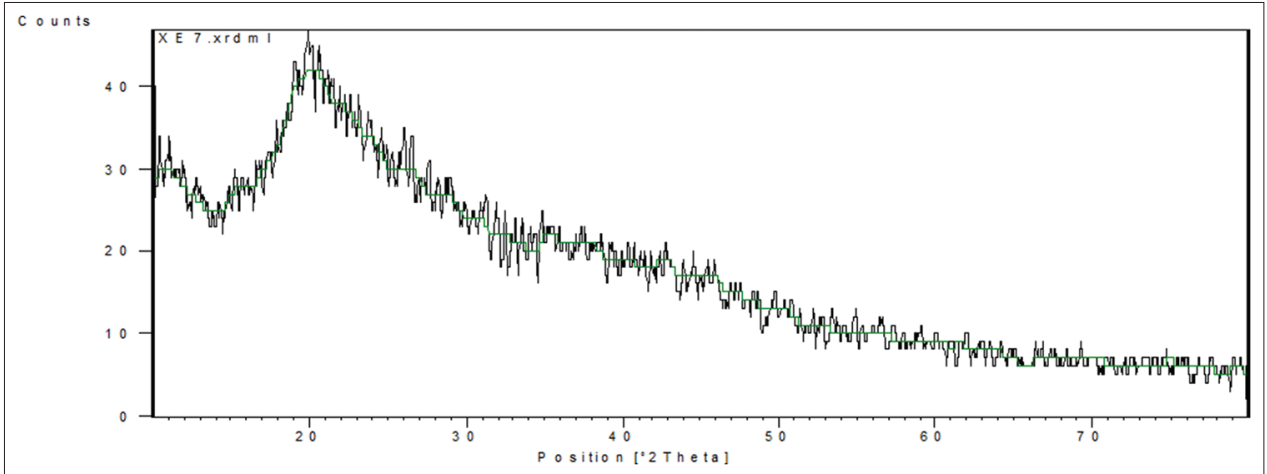

Fig. 15: X-ray powder diffraction spectrum of optimized formulation (E7)

\section{AUTHOR'S CONTRIBUTION}

T. Balakrishna has performed the basic methodology of this work. S. Vidyadhara has guided the entire formulation and principle of the research work. T.E.G.K. Murthy has helped in the formulation studies. A. Ramu helped in the interpretation of DSC data. R.L.C. Sasidhar helped in the interpretation of SEM data.

\section{CONFLICTS OF INTEREST}

The authors have no conflicts of interest.

\section{REFERENCES}

1. Kendall MJ. Review article: Esomeprazole-the first proton pump inhibitor to be developed as an isomer. Aliment Pharmacol Ther 2003;17 Suppl 1:1-4.

2. Patel SR, Patel PR, Vora CN, Patel ND, Patel JK. Optimization and evaluation of delayed release tablets of rabeprazole sodium. Int $\mathrm{J}$ Pharmacy Pharm Sci 2011;2:144-56.

3. Chen CY, Lu CL, Luo JC, Chang FY, Lee SD, Lai YL, et al. Esomeprazole tablet vs omeprazole capsule in treating erosive esophagitis. World J
Gastroenterol 2005;11:3112-7.

4. Miner P Jr. Katz PO, Chen Y, Sostek M. Gastric acid control with esomeprazole, lansoprazole, omeprazole, pantoprazole, and rabeprazole: A five-way crossover study. Am J Gastroenterol 2003;98:2616-20.

5. Edwards SJ, Lind T, Lundell L. Systematic review: Proton pump inhibitors (PPIs) for the healing of reflux oesophagitis-a comparison of esomeprazole with other PPIs. Aliment Pharmacol Ther 2006;24:743-50

6. Moayyedi P, Talley NJ. Gastro-oesophageal reflux disease. Lancet 2006;367:2086-100

7. Hatlebakk JG. Review article: Gastric acidity-comparison of esomeprazole with other proton pump inhibitors. Aliment Pharmacol Ther 2003;17 Suppl 1:10-5.

8. Narwal S, Saini V. Formulation, development and evaluation of fast disintegrating thin film of esomeprazole magnesium trihydrate. Am J Pharm Tech Res 2016;6:520-42.

9. Abouhussein DM, El-Bary AA, El Nabarawi SH. Chitosan mucoadhesive buccal films effect of different casting solvents on their physicochemical properties. Int J Pharm Pharm Sci 2016;8:206-13.

10. Yassina BG, Abassb HA. Design and evaluation of fast dissolving oro-dispersible films of metoclopramide hydrochloride using 32 multifactorial designs. Int J Pharm Pharm Sci 2016;8:218-22. 